\title{
Migration control: a distance compensation strategy in ants
}

\author{
Thomas A. O'Shea-Wheller ${ }^{1}$ - Ana B. Sendova-Franks ${ }^{2}$ - Nigel R. Franks ${ }^{1}$
}

Received: 31 May 2016 /Revised: 10 June 2016 / Accepted: 14 June 2016 / Published online: 18 July 2016

(C) The Author(s) 2016. This article is published with open access at Springerlink.com

\begin{abstract}
Migratory behaviour forms an intrinsic part of the life histories of many organisms but is often a high-risk process. Consequently, varied strategies have evolved to negate such risks, but empirical data relating to their functioning are limited. In this study, we use the model system of the househunting ant Temnothorax albipennis to demonstrate a key strategy that can shorten migration exposure times in a group of social insects. Colonies of these ants frequently migrate to new nest sites, and due to the nature of their habitat, the distances over which they do so are variable, leading to fluctuating potential costs dependent on migration parameters. We show that colonies of this species facultatively alter the dynamics of a migration and so compensate for the distance over which a given migration occurs. Specifically, they achieve this by modulating the rate of 'tandem running', in which workers teach each other the route to a new nest site. Using this method, colonies are able to engage a larger number of individuals in the migration process when the distance to be traversed is greater, and furthermore, the system appears to be based on perceived encounter rate at the individual level. This form of decentralised control highlights the adaptive nature of a behaviour of ecological importance, and indicates that the key to
\end{abstract}

Communicated by: Sven Thatje

Electronic supplementary material The online version of this article (doi:10.1007/s00114-016-1386-8) contains supplementary material, which is available to authorized users.

Thomas A. O'Shea-Wheller to13870@bristol.ac.uk

1 School of Biological Sciences, University of Bristol, Life Sciences Building, 24 Tyndall Avenue, Bristol, UK

2 Department of Engineering Design and Mathematics, UWE Bristol, Frenchay Campus, Coldharbour Lane, Bristol, UK its robustness lies in the use of simple rules. Additionally, our results suggest that such coordinated group reactions are central to achieving the high levels of ecological success seen in many eusocial organisms.

Keywords Cost-benefit trade-offs · Decentralised systems · Ecological robustness · Group migration · Temnothorax albipennis

\section{Introduction}

Cost-benefit trade-offs are common to almost all life history strategies. Animals need to be able to respond to hostile environmental conditions such as extremes of temperature and predation risk (Creel \& Winnie 2005; Hunter 2005; Nonacs \& Dill 1990). Indeed, many life history events involve increased exposure to hazards, but are nevertheless crucial for survival, making a degree of risk essentially unavoidable (Thirgood et al. 2004; Cerdá et al. 1998; Franks \& Fletcher 1983; Guillemette et al. 2012). As a consequence, strong selection pressures are likely to exist for strategies that mitigate the dangers of high-risk but necessary behaviours, and a myriad of such responses may be seen in nature. These range from vigilance behaviour in meerkats (le Roux et al. 2009) and camouflage in numerous species of mammal (Stevens \& Merilaita 2009) to escape reflexes and group defence in migrating invertebrates (Wine \& Krasne 1972; Scho 2005).

Social insects also face such challenges, but their responses often become manifest at the group or colony level, rather than at the individual level (Mlot et al. 2011). This enhanced cooperative ability is thought to be a central tenet of their remarkable ecological success (Hunt et al. 2010). A key aspect of the ability of social insect colonies to coordinate group behaviours is the need for reliable and rapid information relating to the 
immediate environment, with examples encompassing sensing of temperature (Rosengren et al. 1987), perception of the intensity of predation (O'Shea-Wheller et al. 2015; Whitford \& Bryant 1979) and the detection of potentially hostile conspecifics (Franks \& Fletcher 1983). Another factor that influences colony exposure to risk is the distance that must be travelled either as part of foraging, or during migration behaviours. Distance-cost scaling can be observed in vertebrate foraging (Lima 1985), and is likely also to apply to social insects, as the time that individuals spend away from the safety of their nest necessarily increases as a function of distance travelled (Traniello 1989). Consequently, many species of social insects have evolved methods of estimating distances to food sources and potential new nest sites. For example, there is evidence that bees measure distance using both optic flow odometry and path integration, helping them to find desirable resources and relay their location to other colony members (Srinivasan et al. 1997; Chittka et al. 1995). Within the Formicidae, the desert-dwelling ant Cataglyphis fortis also uses path integration, but based on a combination of celestial compass cues and pedometry, allowing reliable navigation in its expansive and relatively featureless environment (Wittlinger et al. 2006; Wehner 2009). However, there are fewer studies relating to how social insects may use such information to reduce mortality and risk of disorientation at the group level.

The ant Temnothorax albipennis is a model species that is well suited to testing how an increase in perceived risk may influence colony-level behaviour. Colonies of this species live within fragile rock cavities in a highly heterogeneous environment, and will migrate into better structures under both field and laboratory conditions, whenever the opportunity is presented. Colony migrations to new nest sites thus make up a crucial part of the species' life history, but at the same time represent a high-risk process, whereby the vulnerable brood and all colony members are exposed (Dornhaus et al. 2004). Furthermore, the distance between the old and new nests influences total migration rate and thus is inseparably linked to the total level of risk during any given migration. Migration distances are highly variable; colonies will migrate into a better quality nest even if it is as far as $2.85 \mathrm{~m}$ from their current one, or as close as $10 \mathrm{~mm}$ (Franks et al. 2008). As such, it seems likely that $T$. albipennis colonies employ strategies to minimise risk when conducting migrations over longer distances, and there are several candidate behaviours that may be involved in this. Perhaps most important in ensuring the continuity and speed of migrations is a behaviour known as tandem running. This involves an ant that knows the location of the new nest leading another colony member to that nest and thus teaching it the route, and is implicated in migration rate and distance assessment (Hölldobler \& Wilson 1990; Franks \& Richardson 2006).

Here, using migrating colonies of T. albipennis, we aim to test whether the distance that must be travelled to a new nest affects the expression of important migration behaviours. Longer migration distances are likely to increase the time that workers spend travelling between nests, prolonging their exposure period, and thus the degree of risk (Langridge et al. 2008). Hence, we predict that colonies will be able to compensate for distance. To assess any such strategies, in our experiments, we provide colonies with both 'near' and 'far' new nest sites and allow them to migrate. During migrations, their current nests are left intact, acting to prolong the decision-making process and allowing us to measure more finely the dynamics of colony relocation (Dornhaus et al. 2004).

In this study, we focus on several key migration behaviours. First, we record the amount of forward and reverse tandem running conducted by colonies. Tandem running involves informed workers leading naïve colony mates to a new nest site (forward tandem running), or from the new site back to their old nest (reverse tandem running), in order to teach them the relative locations of each (Franks \& Richardson 2006). Tandem runs are crucial to the progression of migrations, as movement requires an active 'corps' of spatially informed workers (Franks et al. 2009). Second, we quantify aspects of quorum sensing. This is a process in which ants assess the number of nest mates within a potential new nest site, and once the population in a candidate site reaches a certain value, termed the 'quorum threshold' ants will switch from slow tandem running to rapid social carrying, a transition known as 'quorum attainment' (Franks et al. 2015). Quorum sensing, by which ants assess the quorum threshold, is thus central to solidifying a colony's target nest choice and in implementing the subsequent migration process. Third, we measure the per capita rate of social carrying, in which workers, informed of a new nests location via tandem running, rapidly carry their colony mates to the new nest site, once a quorum threshold has been achieved (Planqué et al. 2007). Social carrying allows migrations to proceed rapidly after a decision has been made, as it is three times faster than tandem running (Planqué et al. 2007).

We hypothesise that when nest sites are further away, colonies will increase the use of behaviours implicated in the rapidity of migrations, such as forward and reverse tandem running. Furthermore, it may be postulated that over longer distances, workers might employ a lower quorum threshold, in order to commit to a new nest more rapidly, begin carrying nest mates sooner, and thus expedite the migration. By analysis of such metrics, in concert with migration rates over different distances, we aim to assess how, and indeed whether, colonies make adjustments in order to counteract the increased danger posed by longer migrations.

\section{Materials and methods}

\section{Colonies}

We collected 30 colonies of $T$. albipennis from the Isle of Portland, Dorset $\left(50.547889^{\circ} \mathrm{N},-2.448251^{\circ} \mathrm{W}\right)$, on 22 
January 2015. Each contained a queen, from 45 to 397 workers, and 11 to 356 brood items (eggs, larvae and pupae). No permission for collection was required as T. albipennis is not a protected species and colonies were taken from a disturbed quarry area with free public access. However, care was taken to keep disturbance of the population to a minimum by use of a rota based on the dates and locations of previous collections. Colonies were maintained under standard laboratory conditions, and all nests were housed in plastic Petri dishes with Fluon-coated sides to avoid worker escape. Ants were fed with Drosophila melanogaster weekly, and allowed to forage for water and honey solution ad libitum in accordance with established upkeep methods (Dornhaus et al. 2004).

Nests of two different qualities (Franks et al. 2003) were used in the experiments, both with an internal cavity area of $60 \times 35 \mathrm{~mm}$. 'Poor' quality nests, in which all colonies were initially housed, had 1-mm-high walls, a 6-mm-wide entrance and a clear cover. 'Excellent' quality nests, into which colonies were able to migrate during trials, had 2-mm-high walls, a 1-mm-wide entrance and a red filter cover. The poor nests had transparent lids to simulate cavities that were compromised by high light levels. The use of red filters in excellent nests ensured lower perceived light levels (Ogawa et al. 2015). This made them preferable to migrating ants, but at the same time did not obscure the observation of individuals within these nests (Franks et al. 2006).

\section{Treatment groups}

After collection, all colonies were allowed to migrate into initial poor quality nests and left to acclimatise for a period of 7 days. This acclimatisation interval was used as colonies gain experience with multiple migrations, leading to changes in decision speed, and such experience is lost only after 7 days of inactivity (Langridge et al. 2004). Prior to initiation of the experiments, we grouped each of the 30 colonies into sets of 3 based on size, then randomly assigned each colony to one of the following three experimental groups: the 'near nest' group, the 'distant nest' group and the 'delayed near nest' group. Each colony underwent only the experimental trial to which it was assigned and emigrated only once. New nests in the 'delayed near' treatment were no further away than in the 'near' treatment but were only placed into arenas after a substantial time interval of $90 \mathrm{~min}$. This 90 -min interval was chosen as it allowed time for scouts to reach and explore the area in which the new nest would eventually be placed. The purpose of this treatment was to assess whether the time a colony spent scouting in an area before a new nest site was found affected the perceived accessibility of such a nest, and thus elicited changes in migration behaviour.

\section{Experiment protocol}

A total of 30 emigrations were conducted over a 19-day period from the 2nd to the 20th of February, 2015. Experiments were performed in $1900 \times 1000$-mm plastic arenas with Fluoncoated sides (Fig. 1). These large arenas were built in order to ensure an extensive potential scouting area, and thus better simulate natural conditions, as ants of this species have been known to migrate into new nest sites up to $2850 \mathrm{~mm}$ away (Franks et al. 2008). Two trials were conducted each day simultaneously, in order to limit the total experimental duration.
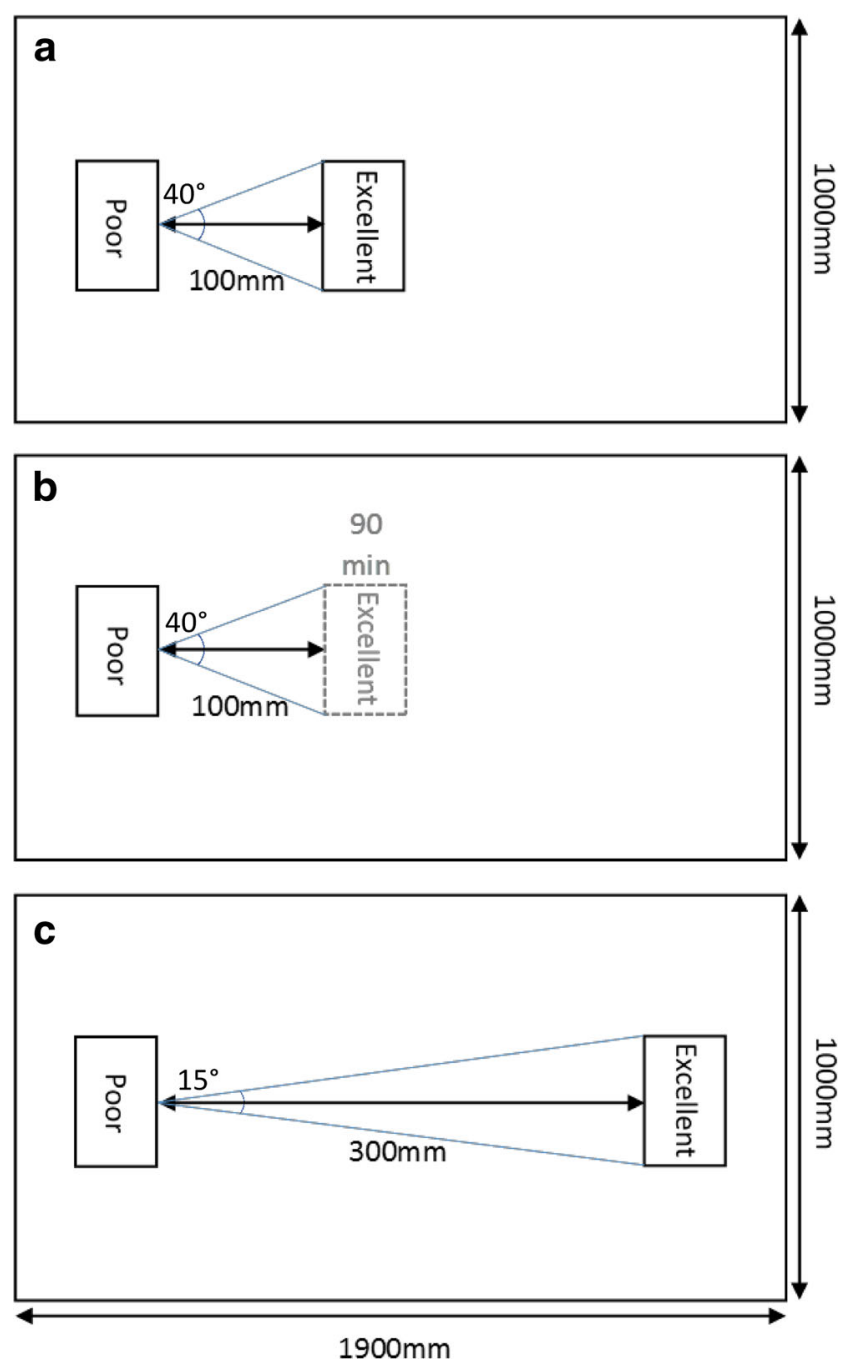

Fig. 1 Layout of experimental arenas for a the near treatment; $\mathbf{b}$ the near delayed treatment, in which the excellent new nest was only placed into the arena after $90 \mathrm{~min}$; and $\mathbf{c}$ the distant treatment. Starting nests housing Temnothorax albipennis ant colonies were of poor quality and were not destroyed, allowing voluntary emigrations to occur. The search angles leading to discovery of new nests are indicated; all new nest sites were of excellent quality. Figure aims to demonstrate nest quality setup and thus is not to scale 
This was desirable, as T. albipennis colonies show seasonality, and thus, shorter experimental periods are required for behavioural consistency (Franks et al. 2006). The order of treatments used was also randomised to make sure that no unintended time-related biases occurred. Prior to each trial, the arenas were cleaned with alcohol and water to remove any odours, and lit evenly using an overhead LED lighting unit (colour rendering index 85, luminous flux 4100).

Occupied poor nests were placed into fixed positions in the arenas, and new excellent nests were placed at set distances from these, dependent on the treatment group. For the near nest group, new nests were positioned so that their entrance was $100 \mathrm{~mm}$ from the starting nest, whilst for the distant nest group, new nests were set up at a distance of $300 \mathrm{~mm}$ (Fig. 1a, c). The potential search angles that allowed discovery of these nests were measured by extrapolating the front face size of new nests over the distance to the original nest entrance and then quantifying the angle with a protractor (Fig. 1). New nests were placed into the open arenas as the use of bridges or channels would artificially lead ants towards them, and thus remove any potential differences in nest discovery frequency. The delayed near nest treatment was also set up with a 100-mm separation to ensure consistency. In the delayed near treatment, the new nest was only placed into the arena $90 \mathrm{~min}$ after the nest occupied by the colony, and recording began only after the 90-min lag period (Fig. 1b). During the movement of nests into the arenas, any scouts that were outside their nests in the original Petri dishes were placed onto the tops of the starting nests within the arenas, using a fine paint brush to minimise disturbance. This was done in order to avoid any scouting discrepancies caused by different initial locations of scouts. From this point, we allowed emigrations to proceed whilst recording the number of workers and brood in each nest every $10 \mathrm{~min}$ for the first $180 \mathrm{~min}$. We also recorded, via direct counts, the timings of new nest discovery, first tandem run, quorum attainment (measured by first instance of social carrying) and the amount of time that first discoverers spent in each new nest. Additionally, we quantified the per capita number of forward and reverse tandem runs, relative quorum threshold and per capita number of worker and brood social carries, with tally counts. Relative rather than absolute quorum threshold was used for consistency and comparability, as quorum threshold scales linearly with colony size (Dornhaus and Franks 2006). As migrations were generally slow and all behaviours were distinct, recordings were made manually, in accordance with established laboratory techniques (O'Shea-Wheller et al. 2015). If migrations were not completed within $180 \mathrm{~min}$, colonies were left for a further $24 \mathrm{~h}$ before returning them to their holding dishes. For incomplete migrations, all relevant behaviours that occurred up to the end of the 180-min observation period were included in the analyses, but no data were recorded after this point.

\section{Data analysis}

In the analysis of all factors, Shapiro-Wilk tests were employed to determine if the data differed significantly from a normal distribution. For normally distributed data with homogeneous variance, we used one-way ANOVA with Tukey's HSD post hoc tests to analyse differences between treatment groups. Where the data was found to be not normally distributed, we transformed it using either arcsine square root, or $\log 10$ transformations, dependent on its skewness. This was done to ensure homogeneity of statistical testing methods. Means quoted from this data were reverse transformed after calculation. Transformations did not alter the pattern of statistical significance, confirmed by testing data before and after transformation, with both parametric and non-parametric tests. For per capita forward and reverse tandem running, relative quorum threshold and the per capita rate of social carrying, data were normalised for colony size. This was achieved by calculating values in proportion to colony population, in order to determine the per capita expression of a behaviour based on the number of available individuals.

We used a Kaplan-Meier survival analysis to assess the effect of treatment group on the mean percentage of ants and brood building up in new nests over time. We used means of the data to produce a cumulative survival function, and ants and brood that moved after 180 mins were treated as censored points. Pairwise comparisons were made using the MantelCox test, for which alpha was 0.016 based on a Bonferroni's correction for the three possible pairwise comparisons between treatment groups. All analyses were conducted in SPSS (Release version 21.0.0.0, IBM Corporation and other(s) 1989, 2012).

\section{Results}

\section{Behavioural phases and tandem running}

The timings of nest discovery (one-way ANOVA, $F_{2,27}=17.439, P<0.001$ ), first tandem run (one-way ANOVA, $\left.F_{2,27}=13.384, P<0.001\right)$ and quorum attainment (one-way ANOVA, $F_{2,27}=7.543, P=0.023$ ) were significantly affected by treatment group. This was due to the timings of nest discovery (means near $=11.94 \mathrm{~min}$, near delayed $=6.66 \mathrm{~min}$, distant $=14.15 \mathrm{~min}$ ), first tandem run (means near $=32.80 \mathrm{~min}$, near delayed $=19.74 \mathrm{~min}$, distant $=57.82 \mathrm{~min}$ ) and quorum attainment (means near $=69.26 \mathrm{~min}$, near delayed $=54.12 \mathrm{~min}$, distant $=$ $115.57 \mathrm{~min}$ ) within the near nest and delayed near nest treatments occurring significantly earlier than in the 
distant nest treatment. Principally, these results can be explained by the increased difficulty of finding new nests in the distant treatment and consequent slowing of migration progression.

The per capita number of tandem runs also varied significantly between groups (one-way ANOVA, $F_{2,27}=4.559$, $P=0.020$ ). Specifically, there was a higher per capita number of tandem runs in the distant nest treatment than in either the near nest (Tukey's HSD, mean difference $=-0.106, P=$ 0.048 ) or delayed near nest (Tukey's HSD, mean difference $=$ $-0.115, P=0.030$ ) treatments (Fig. 2). This was likely caused by a lower rate of independent nest discovery by workers in the distant treatment; thus, more tandem runs were needed to reach a quorum threshold in this group.

The relative quorum threshold (one-way ANOVA, $F_{2,27}=1.240, P=0.305$ ), per capita rate of social carrying (one-way ANOVA, $F_{2,27}=0.570, P=0.572$ ) and time that first discoverer spent in nest (one-way ANOVA, $F_{2,27}=$ 1.179, $P=0.323$ ) did not differ significantly between treatments. Such a consistent relative quorum threshold is contrary to our hypothesis that lower thresholds may be employed over longer distances, and may be accounted for by the move-toimprove conditions used in our experiments (Dornhaus et al. 2004). Furthermore, the lack of change in social carrying rates may possibly be explained by the comparable relative quorum thresholds between treatments. Similar quorums suggest that the average numbers of workers in the new nests at the beginning of carrying were similar in each treatment, and these workers were then the ones that contributed to the carrying process. As such, numbers of carriers were unlikely to differ between treatments, despite changes in tandem running. Lastly, as new nest qualities were always excellent, it is not necessarily surprising that discoverers spent a consistent time within them, regardless of distance. The percentage of ants in the new nest at the time of first tandem run (initial independent discoveries; one-way ANOVA, $F_{2,27}=1.441, P=0.254$; means near $=2.750 \%$, near delayed $=2.165 \%$, distant $=$
$1.184 \%)$ and the number of reverse tandem runs per capita (one-way ANOVA, $F_{2,27}=0.355, P=0.704$ ) also did not differ significantly between treatments.

\section{Progression of migrations}

The average percentage of ants building up over time in the new nests was significantly different between groups (MantelCox test statistic $=17.349, d f=2, P<0.001)$. Specifically, this was explained by differences between the near nest and distant nest treatments (Mantel-Cox test statistic $=13.708, d f=1$, $P<0.001)$ and delayed near nest and distant nest treatments (Mantel-Cox test statistic $=15.700, d f=1, P<0.001)$. However, the near nest and delayed near nest treatments were not significantly different (Mantel-Cox test statistic $=0.375$, $d f=1, P=0.540$; Fig. 3 ). This suggests that the longer journey to nests in the distant treatment lead to a reduction in migration rate, but that this was not the case in either the near or delayed near treatments, both being equidistant from the original nest.

The average percentage of brood building up in the new nest over time was also significantly different between groups (Mantel-Cox test statistic $=69.132, d f=2, P<0.001$ ). Significant differences occurred between the near nest and distant nest treatments (Mantel-Cox test statistic $=46.416$, $d f=1, P<0.001)$ and delayed near nest and distant nest treatments (Mantel-Cox test statistic $=72.298, d f=1, P<0.001$ ). However, again the near nest and delayed near nest treatments were not significantly different (Mantel-Cox test statistic $=$ 3.375, $d f=1, P=0.066$; Fig. 3). These results point to the same trend as seen in worker movement, whereby only increased distance led to a slower migration. Notably, overall brood transport was faster than the movement of workers. This is because brood items are immobile, and due to their vulnerability, are rapidly moved to the new nest with preference over adults (Langridge et al. 2008).

The percentages of workers (one-way ANOVA, $F_{2,27}=2.798, P=0.079$ ) and brood (one-way ANOVA,
Fig. 2 Mean number of tandem runs (per capita) across treatments. Significant differences between groups $(P<0.05)$, based on ANOVA analysis and Tukey's HSD post hoc tests, are indicated with asterisks. $N=10$ colonies were used in each treatment; error bars indicate $95 \%$ confidence intervals

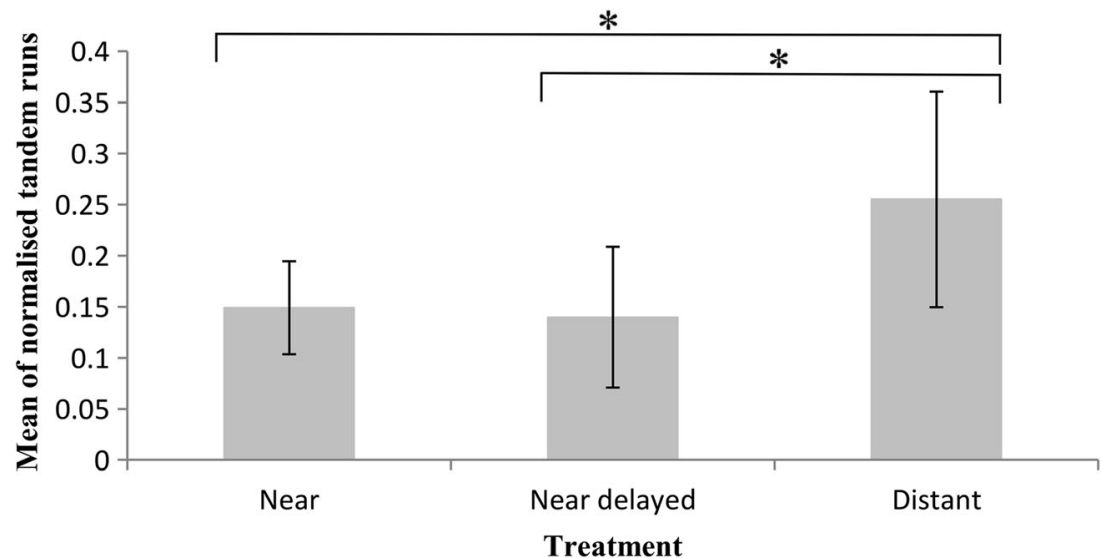


Fig. 3 Mean percentage of total colony workers (a) and brood (b) in the new nests over time for each of the three treatment groups. Blue lines indicate the near treatment, grey lines indicate the near delayed treatment and black lines indicate the distant treatment. In the near delayed treatment, colonies were allowed to scout for $90 \mathrm{~min}$ but with no new nest present until time 0 . The mean represents $n=10$ colonies for each time point; asterisks indicate the mean time of first brood transport (quorum attainment), in each correspondingly coloured group. All error bars indicate $95 \%$ confidence intervals
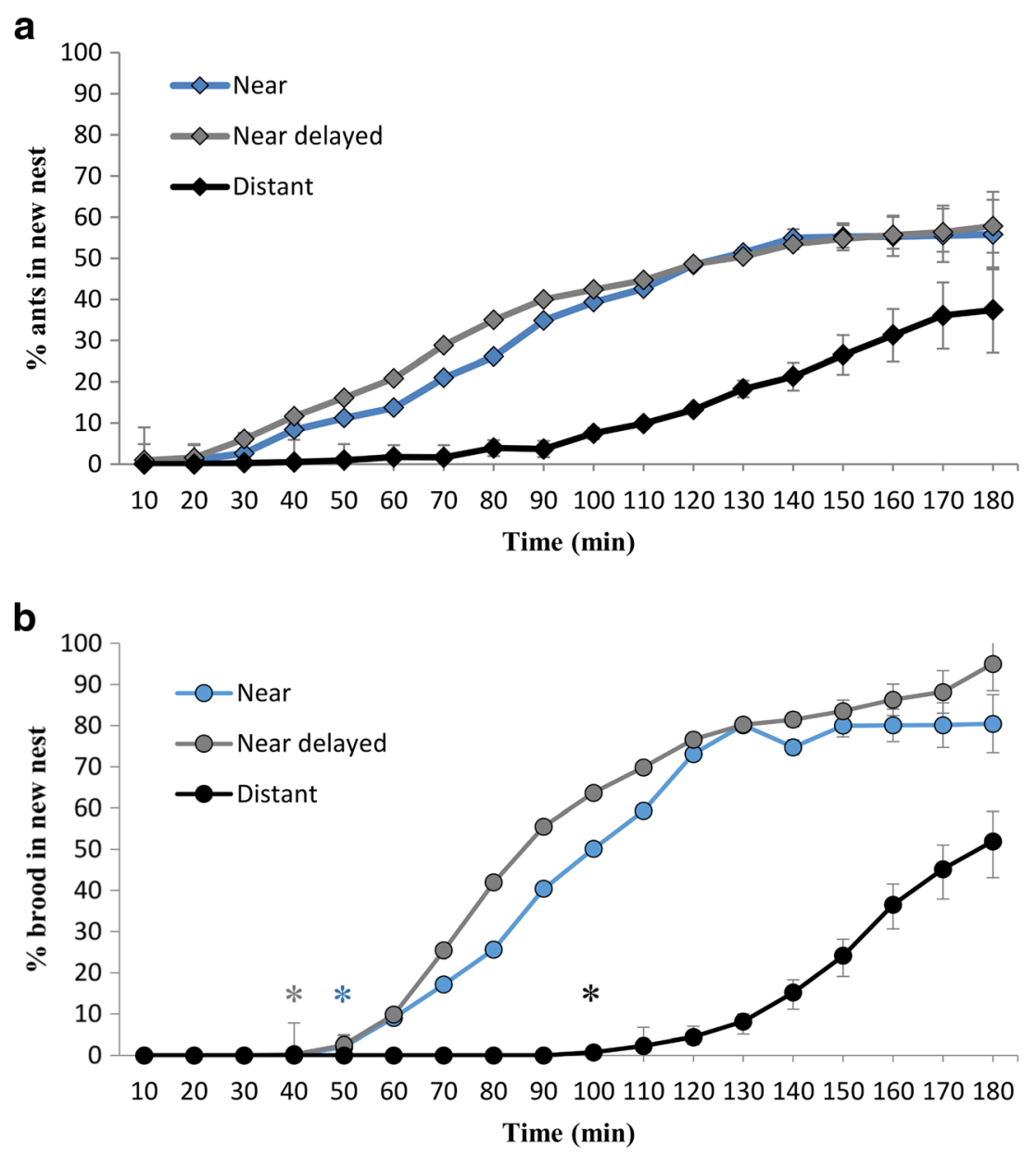

$\left.F_{2,27}=3.178, P=0.058\right)$ in the new nests at the final time points did not differ significantly between treatment groups, but it must be noted that values in the distant treatment were still lower for both measures, and both $p$ values were small even if above 0.05 (Fig. 4). This is indicative of a partial, but incomplete, adjustment of migration rates by the end of the process.

\section{Discussion}

We show that colonies of $T$.albipennis can respond to differing migration conditions via the regulation of tandem running behaviour. Specifically, we found that colonies will increase the per capita number of tandem runs used during an emigration when the distance to be traversed is greater (Fig. 2). In this way, migration transit time is minimised and exposure period is reduced. Furthermore, we found that the end result of migrations after $180 \mathrm{~min}$ across colonies was comparable regardless of the distance travelled (Fig. 4), but that the underlying dynamics varied significantly (Figs. 2 and 3). This indicates that colonies increase the rate of tandem running when a new nest is further away, in order to expedite the migration process, by increasing the rate at which workers discover the new nest (Stuttard et al. 2015). Our results demonstrate that travel distance significantly affects colony migration strategy in moveto-improve scenarios, and additionally, they highlight the importance of perception at the individual level in influencing collective behaviour.

Independent discoveries - that is ants finding the new nest without being led to it-were less frequent in the far nest treatment than in the near or near delayed treatments. This was characterised by the buildup of ants in the new nests prior to the initiation of tandem running, as all individuals present at this time made independent discoveries. The numbers of ants in new nests at the time of the first tandem run did not differ significantly between treatments, suggesting that tandem running began at a set nest population. However, crucially, along with quorum attainment, the first tandem run occurred later in the distant nest treatment (Fig. 3). This showed that more time was required to reach such a population and was indicative of a lower discovery rate when the nest was further away. Furthermore, the search angle leading to discovery of the front surfaces of the new nests in the near and delayed near 
a

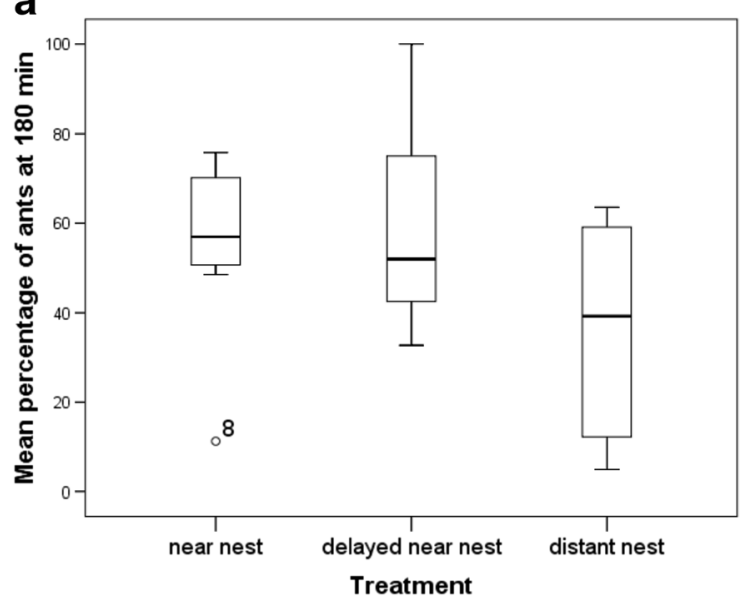

Fig. 4 Boxplots for percentages of ants (a) and brood (b) in the new nests at $180 \mathrm{~min}, n=10$ colonies per treatment. Boxes are cut at the median, with the upper and lower limits of the box representing the upper and

treatments $\left(40^{\circ}\right)$, was more than double that of the distant treatment $\left(15^{\circ}\right.$; Fig. 1), indicating that distant nests were harder to find, and additionally presented smaller vertical landmarks. Indeed, such differences are ecologically relevant to the probability of nest discovery, principally because ants of this species do use visual landmarks, and upon contact with the front of a nest, scouting workers will often employ thigmotaxis to locate its entrance (Basari et al. 2014; Hunt et al. 2014).

As distant nests were more difficult to discover, the role of increased numbers of tandem runs was clear; they led to an increase in the discovery rate and thus generated a larger pool of informed workers, potentially able to contribute to the carrying stage of the migration (Franks \& Richardson 2006; Planqué et al. 2007). Conversely, the absence of this process in the delayed near nest treatment can be explained because such nests were no further away than in the near treatment. Without an increased travel distance, the independent discovery rate and time taken to recruit naive ants to the new nest would not have differed between workers in the two near treatments. Hence, there was little stimulus for colonies to compensate based on perception at the individual level, despite delayed nest discovery. This is advantageous, as in their natural habitat, nest discovery times are likely to be more variable due to non-uniform environmental features. In light of this, it is reasonable to assume that colonies accounted for the increased distance between nests without the use of discovery time as a proxy.

Although the use of landmarks and pedometry have been implicated in nest location during tandem running (Franklin \& Franks 2012; Basari et al. 2014), here, a system based on independent discovery rate provides a more parsimonious b

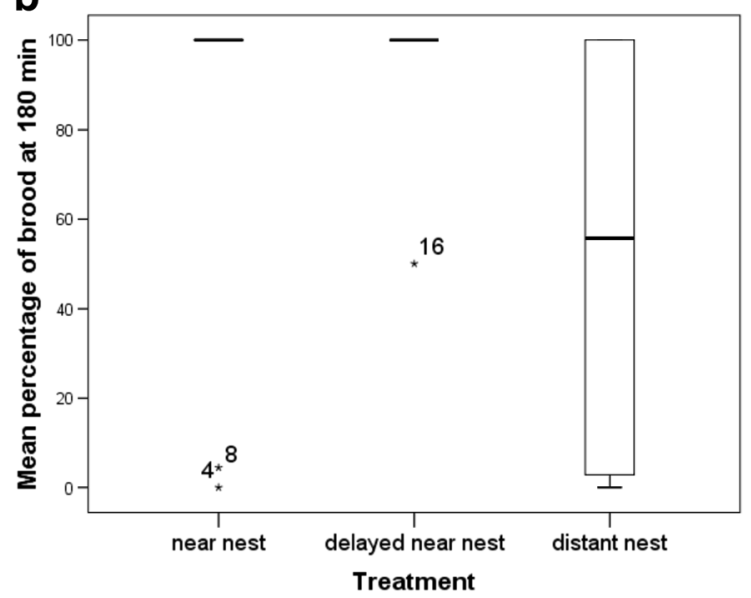

lower quartiles, respectively. Outliers (further than 1.5 times the interquartile range from the median) are marked with circles (ants) and asterisks (brood); numbers indicate colony IDs explanation for our results (Pratt 2004). When nests are nearby, exploring workers are likely to find them relatively easily. However, this is not the case when they are distant. Hence, more tandem runs are required over longer migration distances simply because independent discoveries are rarer, and thus, more ants must be led to a nest before a quorum threshold can be reached. In this way, workers do not measure distance directly, but instead respond to quorum attainment, a factor that in this case was influenced by distance (Pratt 2004). It is known that T. albipennis workers use encounter frequency to measure nest size and quorum threshold (Stuttard et al. 2015; Pratt 2004) and that tandem running will continue up until the point that a quorum threshold is reached (Planqué et al. 2007). Lower discovery rates extend the pre-quorum period, as seen in the distant treatment, and so a greater proportion of ants in the new nest are led there by tandem runs. As such, the greater number of tandem runs is likely a selfregulating process, controlled by quorum attainment alone, rather than by actual distance measurement.

The aforementioned self-organisation hypothesis is consistent with earlier work on T.albipennis, T.curvispinosus and T.rugatulus, suggesting that when independent nest discoveries were more common, the rate of tandem running decreased (Mallon et al. 2001; Pratt 2008). Notably, whilst these studies used forced migrations, involving the destruction of colonies' original nests, our own data appear to corroborate their findings in relation to environmentally common move-to-improve migrations, in which tandem running plays a greater role (Dornhaus et al. 2004). Tandem runs to near nests are rare or absent under emergency migration conditions (Dornhaus et al. 2004), but in our experiments, all colonies in the near treatment still engaged in this behaviour. Indeed, there is a clear 
advantage to doing so under benign conditions, as during the tandem running stage, colonies are still open to switching to a better nest site if one is discovered, whilst this is no longer the case once they commit to carrying (Franks et al. 2007; Sasaki et al. 2015).

There is a substantial body of literature implying that for any given migration, quicker is better (Langridge et al. 2008; Scharf et al. 2012; Franks et al. 2009; Franks et al. 2008), and colonies in our experiment did attempt to expedite migrations. In spite of this, we found that longer migration distances still led to slower movement, even with the partial rescuing of migration rate by increased tandem running (Figs. 3 and 4). This highlights the often-incomplete nature of compensatory behaviours, and suggests that for T.albipennis colonies, increased migration distance may always impart some degree of cost.

Whilst tandem running is a crucial behaviour implicated in regulating migrations (Franks \& Richardson 2006), there is also evidence to suggest that reverse tandem runs; from the new to the old nest, play a role in modulating migration rate (Franks et al. 2009). However, we found no significant effect of migration distance on the number of reverse tandem runs. This result may be explained by the findings of previous empirical studies, showing that increased numbers of reverse tandem runs are induced only by disorientation of active scouts. Such studies indicate that the primary purpose of reverse tandem running is to re-engage 'lost scouts' in the migration process, rather than to train naïve workers (Planqué et al. 2007; Franks et al. 2009). In our experiments, distance was the key limiting factor; thus, it was preferable to engage as many new workers in the tasks of recruitment and carrying, a process achieved by the use of forward tandem runs alone (Franks \& Richardson 2006). As such, it is probable that colonies facultatively alter both forward and reverse tandem running to control migration rate, dependent on the particular challenges that threaten to curtail it.

Building on the work of Pratt (2004), we show the potential for colonies to modulate their behaviour in response to distance, using a decentralised system based on perception at the individual level. Indeed, it may well be argued that for the purposes of migration in T.albipennis, such a comparatively simple system provides superiority in both rapidity and robustness when juxtaposed against more sophisticated distance assessment methods (Thiélin-Bescond \& Beugnon 2005). Furthermore, the specific costs addressed by this process are of particular ecological significance, as migration distances vary widely in nature (Franks et al. 2008).

Our work demonstrates an example of colony-level risk mitigation behaviour, which, taken with other such examples (O'Shea-Wheller et al. 2015; Gordon et al. 2007), further illustrates the enhanced ability of social insects to adapt and respond to risks over a range of spatial and temporal scales. Moreover, as is the case with numerous other complex systems (Siljak 2012; Zimmerman et al. 2014), the key to this behaviour lies in its decentralised control. Thus, we provide further evidence that the robustness of self-organised systems is one of the central factors enabling eusocial animals to meet ecological challenges.

Author contributions TAOW and NRF conceived the study and wrote the manuscript, TAOW conducted all the experimental work, and TAOW and ABSF carried out the statistical analysis. All authors gave final approval for publication.

\section{Compliance with ethical standards}

Conflicts of interest The authors declare that they have no conflict of interest.

Data accessibility All data are included in the Electronic supplementary material.

Ethical standard statement All applicable institutional and/or national guidelines for the care and use of animals were followed.

Funding This work received no specific funding.

Open Access This article is distributed under the terms of the Creative Commons Attribution 4.0 International License (http:// creativecommons.org/licenses/by/4.0/), which permits unrestricted use, distribution, and reproduction in any medium, provided you give appropriate credit to the original author(s) and the source, provide a link to the Creative Commons license, and indicate if changes were made.

\section{References}

Basari N, Bruendl AC, Hemingway CE, Roberts NW, Sendova-Franks AB, Franks NR (2014) Landmarks and ant search strategies after interrupted tandem runs. J Exp Biol 217(Pt 6):944-954

Cerdá X, Retana J, Manzaneda A (1998) The role of competition by dominants and temperature in the foraging of subordinate species in Mediterranean ant communities. Oecologia 117(3):404-412

Chittka L, Kunze J, Shipman C, Buchmann SL (1995) The significance of landmarks for path integration in homing honeybee foragers. Naturwissenschaften 82(7):341-343

Creel S, Winnie J a (2005) Responses of elk herd size to fine-scale spatial and temporal variation in the risk of predation by wolves. Anim Behav 69(5):1181-1189

Dornhaus A, Franks NR (2006) Colony size affects collective decisionmaking in the ant Temnothorax albipennis. Insectes Soc 53(4):420 427

Dornhaus A, Franks NR, Hawkins RM, Shere HNS (2004) Ants move to improve: colonies of Leptothorax albipennis emigrate whenever they find a superior nest site. Anim Behav 67(5):959-963

Franklin EL, Franks NR (2012) Individual and social learning in tandemrunning recruitment by ants. Anim Behav 84(2):361-368

Franks NR, Fletcher CR (1983) Spatial patterns in army ant foraging and migration : Eciton burchellii on Barro Colorado Island, Panama. Behav Ecol Sociobiol 12(4):261-270

Franks NR, Richardson T (2006) Teaching in tandem-running ants. Nature 439(7073): 153

Franks NR, Mallon EB, Bray HE, Hamilton MJ, Mischler TC (2003) Strategies for choosing between alternatives with different 
attributes: exemplified by house-hunting ants. Anim Behav 65(1): 215-223

Franks NR, Dornhaus A, Metherell BG, Nelson TR, Lanfear SAJ, Symes WS (2006) Not everything that counts can be counted: ants use multiple metrics for a single nest trait. Proc R Soc Lond Biol 273(1583):165-169

Franks NR, Hooper JW, Gumn M, Bridger TH, Marshall JAR, Groß R, Dornhaus A (2007) Moving targets: collective decisions and flexible choices in house-hunting ants. Swarm Intell 1:81-94

Franks NR, Hardcastle KA, Collins S, Smith FD, Sullivan KME, Robinson EJH, Sendova-Franks AB (2008) Can ant colonies choose a far-and-away better nest over an in-the-way poor one? Anim Behav 76(2):323-334

Franks NR, Dechaume-Moncharmont FX, Hanmore E, Reynolds JK (2009) Speed versus accuracy in decision-making ants: expediting politics and policy implementation. Phil Trans R Soc B 364(1518): 845-852

Franks NR, Stuttard JP, Doran C, Esposito JC, Master MC, SendovaFranks AB, Masuda N, Britton NF (2015) How ants use quorum sensing to estimate the average quality of a fluctuating resource. Sci Rep 5:11890

Gordon DM, Holmes S, Nacu S (2007) The short-term regulation of foraging in harvester ants. Behav Ecol 19(1):217-222

Guillemette M, Richman SE, Portugal SJ, Butler PJ (2012) Behavioural compensation reduces energy expenditure during migration hyperphagia in a large bird. Behav Ecol 26(4):876-883

Hölldobler B, Wilson EO (1990) The Ants. The Belknap press of Harvard University Press, Cambridge, Massachusetts

Hunt BG, Wyder S, Elango N, Werren JH, Zdobnov EM, Yi SV, Goodisman MAD (2010) Sociality is linked to rates of protein evolution in a highly social insect. Mol Biol Evol 27(3):497-500

Hunt ER, O'Shea-Wheller T, Albery GF, Bridger TH, Gumn M, Franks NR (2014) Ants show a leftward turning bias when exploring unknown nest sites. Biol Lett 10(12):20140945

Hunter LM (2005) Migration and environmental hazards. Popul Environ 26(4):273-302

Langridge EA, Franks NR, Sendova-Franks AB (2004) Improvement in collective performance with experience in ants. Behav Ecol Sociobiol 56(6):523-529

Langridge EA, Sendova-Franks AB, Franks NR (2008) The behaviour of ant transporters at the old and new nests during successive colony emigrations. Behav Ecol Sociobiol 62(12):1851-1861

Le Roux A, Cherry MI, Gygax L, Manser MB (2009) Vigilance behaviour and fitness consequences: comparing a solitary foraging and an obligate group-foraging mammal. Behav Ecol Sociobiol 63(8): 1097-1107

Lima SL (1985) Maximizing feeding efficiency and minimizing time exposed to predators: a trade-off in the black-capped chickadee. Oecol 66(1):60-67

Mallon EB, Pratt SC, Franks NR (2001) Individual and collective decision-making during nest site selection by the ant Leptothorax albipennis. Behav Ecol Sociobiol 50(4):352-359

Mlot NJ, Tovey C a, Hu DL (2011) Fire ants self-assemble into waterproof rafts to survive floods. Proc Natl Acad Sci U S A 108(19): 7669-7673

Nonacs P, Dill LM (1990) Mortality risk vs. food quality trade-offs in a common currency: ant patch preferences. Bull Ecol Soc Am 71(5): 1886-1892
O'Shea-Wheller TA, Sendova-Franks AB, Franks NR (2015) Differentiated anti-predation responses in a superorganism. PLoS One 10(11):e0141012

Ogawa Y, Falkowski M, Narendra A, Zeil J, Hemmi JM (2015) Three spectrally distinct photoreceptors in diurnal and nocturnal Australian ants. Proc R Soc Lond Biol 282(1808)

Planqué R, Dechaume-Moncharmont F-X, Franks NR, Kovacs T, Marshall JAR (2007) Why do house-hunting ants recruit in both directions? Naturwissenschaften 94(11):911-918

Pratt SC (2004) Quorum sensing by encounter rates in the ant Temnothorax albipennis. Behav Ecol 16(2):488-496

Pratt SC (2008) Efficiency and regulation of recruitment during colony emigration by the ant Temnothorax curvispinosus. Behav Ecol Sociobiol 62(8):1369-1376

Rosengren R, Fortelius W, Lindström K, Luther A (1987) Phenology and causation of nest heating and thermoregulation in red wood ants of the Formica rufa group studied in coniferous forest habitats in southern Finland. Ann Zool Fenn 24(2):147-155

Sasaki T, Colling B, Sonnenschein A, Boggess MM, Pratt SC (2015) Flexibility of collective decision making during house hunting in Temnothorax ants. Behav Ecol Sociobiol 69(5):707-714

Scharf I, Modlmeier AP, Fries S, Tirard C, Foitzik S (2012) Characterizing the collective personality of ant societies: aggressive colonies do not abandon their home. PLoS One 7(3):e33314

Scho C (2005) Temporal and spatial patterns in the emigrations of the army ant Dorylus (Anomma) molestus in the montane forest of Mt. Kenya. Ecol Entomol 30:532-540

Siljak DD (2012) Decentralized control of complex systems. Dover Publications Inc., Mineola, New York

Srinivasan MV, Zhang SW, Bidwell NJ (1997) Visually mediated odometry in honeybees. J Exp Biol 200:2513-2522

Stevens M, Merilaita S (2009) Animal camouflage: current issues and new perspectives. Phil Trans R Soc B 364(1516):423-427

Stuttard JP, Gottlieb D, Franks NR (2015) Ants incommunicado: collective decision-making over new nest sites by ants with reduced communication. Behav Ecol Sociobiol 70(1):145-155

Thiélin-Bescond M, Beugnon G (2005) Vision-independent odometry in the ant Cataglyphis cursor. Naturwissenschaften 92(4):193-197

Thirgood S, Mosser A, Tham S, Hopcraft G, Mwangomo E, Mlengeya T, Kilewo M, Fryxell J, Sinclair ARE, Borner M (2004) Can parks protect migratory ungulates? The case of the Serengeti wildebeest. Anim Conserv 7(2):113-120

Traniello JFA (1989) Foraging strategies of ants. Annu Rev Entomol 34(1):191-210

Wehner R (2009) The architecture of the desert ant's navigational toolkit (Hymenoptera: Formicidae). Myrmecol News 12(September):8596

Whitford WG, Bryant M (1979) Behavior of a predator and its prey: the horned lizard (Phrynosoma cornutum) and harvester ants (Pogonomyrmex spp.). Ecology 60(4):686-694

Wine BYJJ, Krasne FB (1972) The organization of escape behaviour in the crayfish. J Exp Biol 56:1-18

Wittlinger M, Wehner R, Wolf H (2006) The ant odometer: stepping on stilts and stumps. Science 312:1965-1967

Zimmerman LM, Bowden RM, Vogel LA (2014) A vertebrate cytokine primer for eco-immunologists ed. Funct Ecol 28(5):1061-1073 